\section{Assessing Nozzle Geometry, Spacing and Height Effect on Pesticide Spray Characteristics and Swath from Ground and Aerial Sprayers}

\section{Samuel Appah, PhD}

Key Laboratory of Modern Agricultural Equipment and Technology, Ministry of Education, Jiangsu University, Zhenjiang, China;

Abetifi Presbyterian College of Education,Abetifi Kwahu, Ghana.

\section{Mingxiong Ou, PhD}

Key Laboratory of Modern Agricultural Equipment and Technology, Ministry of Education, Jiangsu University, Zhenjiang, China

\section{Weidong Jia, Professor}

Key Laboratory of Modern Agricultural Equipment and Technology, Ministry of Education, Jiangsu

University, Zhenjiang, China

\section{Eric Amoah Asante, PhD}

Department of Mechanical Engineering, Faculty of Engineering, Koforidua Technical University, Ghana

\section{Wanting Yang, MSc}

Submitted: 23 September 2019

Accepted: 09 January 2020

Published: 31 October 2020

Corresponding author:

Samuel Appah

DOI: 10.19044/esj.2020.v16n30p103

(c)

Copyright 2020 Appah et al.

Distributed under Creative Commons CC-BY 4.0 OPEN ACCESS

\begin{abstract}
:
Nozzle is the basic aperture that controls pesticide spray jet onto targeted substrates. It is moulded from stainless steel, brass, ceramic and plastics at different wear rates. The efficiency of pesticide application is dependent on chemical efficacy and nozzle type. Both flat fan and hollow cone nozzles are commonly used to enhance pesticide spray characteristics and deposition. The surface coverage and spray distribution are influenced by nozzle spacing and spraying height. Therefore, using a nozzle type, spacing and spraying height that give pesticide spray-overlap is of interest to researchers. This review therefore analyses the effect of nozzle geometry, nozzle spacing and spraying height regimes on pesticide spray droplets characteristics from mechanical boom sprayers. To improve on uniformity of pesticides spray coverage on plant surfaces, a unitary relative span is reported suitable for application, but there had not been clearly defined nozzle type, spacing and height regime for effective spraying. The review further proposes an optimum parameters combination with specific nozzle type, spacing and spraying height for efficient application of pesticides.
\end{abstract}

Key Words: Nozzle geometry, nozzle spacing, spraying height, droplets characteristics, spray swath
Subject: Agriculture 


\section{Introduction}

Crop protection from pests, weeds and nutrient effects is crucial in ensuring crop growth and yield. The correct and timely application of pesticides at critical crop growth stages play an important role in maximising yield (Malik et al., 2012). Both organic and synthetic pesticides are applied to crops, but there is much reliance on synthetic pesticides nowadays in crop protection (Cho and Ki, 1999). These pesticides are increasingly being used to improve product grade due to their rapid response. However, the chemicals have an associated effect of reducing product quality by adsorption (Aktar et al., 2009) and causing ecological imbalance by drift (Reus et al., 2002; Coscollà et al., 2017). In spite of the economic benefits of pesticides applications, there exist crops lost to pests and pathogens and to weeds (Adenawoola, 2005). Such crops deterioration and lost phenomenon could be attributed to variant application rates, chemical inefficacy and spray procedures. Therefore, a suitable spray procedure that ensures effective droplets deposition with less residual effect on targeted crop without drift to non-target organisms is required. The pesticide application is mainly facilitated by either a backpack sprayer or power-driven sprayers and the selection of the technology is at the discretion of the farmer.

The mechanical sprayers atomise pesticide formulations and deposit the droplets on crops through nozzles for crop-chemical interactions (Ellis et al., 2008). The nozzle type, nozzle spacing, droplet sizes and velocity determine the spray coverage (Doll et al., 2005; Armstrong-cho et al., 2008; Nuyttens et al., 2010). Also, droplets characteristics are affected by nozzle geometry and pump pressure, whereas substrate coverage is influenced by height regimes and application rate (Ferguson et al., 2016b). Butler Ellis and Tuck (1999) pointed out the relationship between nozzle geometry and formulation properties as a measure of nozzle performance. To achieve maximum spray span and uniformity, there is the need to understand sprayer-operation mechanisms, nozzle geometry, spacing and spraying height regimes. An extensive study on pesticide spraying in crop protection has been carried out. The objective of this review is to analyse the effect of nozzle type, nozzle spacing and spraying height regimes on pesticide spray droplets characteristics from both ground and aerial sprayers. Though the quest for farmers is to have a specific nozzle type at a definite spacing and spraying height regime for all applications, there exist different operating parameters to choose. Therefore, an in-depth knowledge on nozzle geometry, spacing and spraying height regimes is needed to provide an informed decision on nozzle selection and orientation in crop protection to farmers. 


\section{Nozzles Geometry, Materials and Spraying Mechanisms}

Nozzle is a rudimentary mechanism through which liquids are dispersed into spray droplets (Lipp and Charles, 2012). In crop protection, the nozzle is viewed as a precision aperture that distributes water and other chemical formulations to crops. The nozzles pressurise pesticides onto contact surfaces by maximising spray surface area through atomisation (Nasr et al., 2002). Nozzles are classified based on tip configuration and spray droplets formation (ASABE, 2009). Many companies have manufactured variant nozzles for spraying, but few are used in pesticide application (Robert, 2002; Ferguson et al., 2016b). The most commonly used ones are; flat fan including extended range flat, flooding, band spraying, symmetric; and asymmetric twin cone spray such as hollow cone, full cone and streaming nozzles (User's Guide, 2013). Additionally, Chamber and venturi style tips, hydraulic pressure and Spinning disc nozzle types exist (Matthews, 1999; Wolf, 2004; YarpuzBozdogan et al., 2011). The invention of dual fan air-inclusion nozzles are also available at a reduced drift (Nuyttens et al., 2007b). A comparison of nozzle types in terms of performance has been studied (Derksen et al., 2008; Hanna et al., 2009; Guler et al., 2012) and the selection from the nozzles for application is determined by the tip colour embossment, volume mean diameter (VDM) (Table 1) and International Organisation for Standardisation (ISO) number (Nuyttens et al., 2007b; ASABE, 2009).

Table 1: Nozzle Tip Colour Codes, Droplet Description and VDM (ASABE, 2009)

\begin{tabular}{|c|c|c|c|c|c|c|c|c|}
\hline $\begin{array}{l}\text { Colour } \\
\text { Code }\end{array}$ & UC & EC & vc & C & M & $\mathrm{F}$ & VF & XF \\
\hline $\begin{array}{l}\text { Droplets } \\
\text { Attributes }\end{array}$ & $\begin{array}{l}\text { Ultra- } \\
\text { Coarse }\end{array}$ & $\begin{array}{l}\text { Extremely } \\
\text { Coarse }\end{array}$ & $\begin{array}{l}\text { Very } \\
\text { Coarse }\end{array}$ & Coarse & Medium & Fine & $\begin{array}{l}\text { Very } \\
\text { Fine }\end{array}$ & $\begin{array}{l}\text { Extremely } \\
\text { Fine } \\
\end{array}$ \\
\hline VDM & $>665 \mu$ & $\begin{array}{l}503- \\
665 \mu\end{array}$ & $\begin{array}{l}404- \\
502 \mu\end{array}$ & $\begin{array}{l}341- \\
403 \mu\end{array}$ & $\begin{array}{l}236- \\
340 \mu\end{array}$ & $\begin{array}{l}144- \\
235 \mu\end{array}$ & $\begin{array}{l}61- \\
144 \mu\end{array}$ & $<60 \mu$ \\
\hline
\end{tabular}

\subsection{Nozzle Materials and Spraying Mechanism}

The nozzles are manufactured from a single or combination of materials (Wolf, 2002). The body, cap, check valve and tip of the nozzles are made from stainless steel, brass, ceramic and plastics with different wear rates (Hofman and Solseng, 2004). The degree of nozzle wear decreases with the material strength ranging from hardened stainless, stainless steel, plastic to brass, but increases with flow rate from lower to higher (Duvnjak et al., 2009). A $10 \%$ worn out nozzle orifice material results in a non-uniformity of spray coverage and poor chemical spray efficiency (Wolf, 2002). In the determination of a nozzle material responsiveness to wear as pressure increases, stainless steel tip was adjudged the best for working at longer hours than plastic and brass (Duvnjak et al., 2009; Sukumaran et al., 2013). Such a material strength reduces the frequency of changing nozzles during pesticide spraying. The angle to which nozzle tips are calibrated also influences spray 
coverage. Conventional nozzle tips come in different angles of $80^{\circ}, 110^{\circ}$ and $120^{\circ}$ (Wolf, 2002), but widening nozzle tip angle and pressurizing formulation through decrease coefficient of variation (CV), a measure of spray uniformity (Hassen et al., 2013). During nozzle selection, the tip angle that produces at most CV of 7\% is considered suitable (User's Guide, 2013). In the conduit of the nozzle, the liquid jet exits the tip as spray droplets (Figure 1) for droplet sizes determination (Klein et al., 2009).
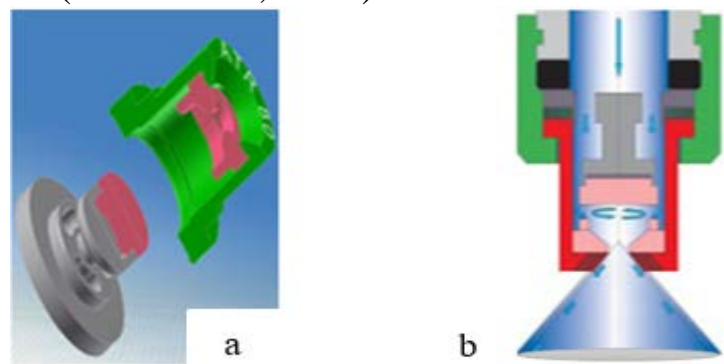

Figure 1. Nozzle; (a) cross-section of an assembled nozzle parts and (b) nozzle spraying jet mechanism

\section{Effect of Nozzle Type on Spray Droplets Characteristics}

Nozzle performance has been studied as a function of the design (Butler Ellis and Tuck 1999). The working ability of flat fan nozzle was observed to be spraying lesser droplets at higher spray angle than hollow cone nozzles (Gaytan et al., 2018). The wider angle is linked to nature of slit at the spout which is broader than point source as envisaged in hollow cone nozzles. Further, in a study to determine the effects of nozzle type, size and pressure on spray droplets characteristics, Nuyttens et al., (2007a) indicated a significant correlation between nozzle geometry, droplet sizes and droplets velocity. The nozzle type determines droplet sizes and drift during spraying (Hanks et al., 2002; Al Heidary et al., 2014). Hollow cone nozzles yield finest droplet sizes at higher drift potential than flat fan nozzles when subjected to similar application conditions. Bueno et al. (2016) asserted that drift is minimised for nozzles that produce larger droplets, which confirmed the research finding that drift from air induction type nozzles was lesser than conventional nozzles (Hanks et al., 2002). Additionally, nozzles having large ISO value produce bigger droplet sizes at lower drift (Nuyttens et al., 2009). For droplets to reach targets at longer distance, the selected nozzle type must exit smaller droplet sizes (Jia et al., 2010). This means that nozzles that produce spray droplet sizes suitable enough to overcome drift and maximise ground coverage is needed in pesticide spraying.

According to Douzals and Al Heidary (2014), the optimal performance of a nozzle type is affected by the prevailing wind condition, except in a tunnel where spray droplets characteristics are controlled and minimally affected by 
nozzle type (Jamar et al., 2010). In addition, the physical properties of a formulation determine the droplet sizes that a particular nozzle type can produce (Hewitt and Hermansky, 1997). In view of that many kinds of nozzles are available to produce different spray droplets characteristics at different drift potential due to different formulation properties (Ferguson et al., 2015). A review by Miller and Butler Ellis (2000) suggested that air induction nozzles are sensitive to formulation properties in which emulsions yield larger droplets. The formulation properties determined droplet sizes with emulsions giving larger droplet sizes than aqueous solutions in an application with flat fan nozzle (Sanderson et al., 1997; Butler Ellis et al., 1997; Mueller and Womac, 1997). It is the quality of water for formulation that changes spray characteristics. This is because hardness of water minimises droplet sizes that nozzles produce (Parafiniuk et al., 2015). But irrespective of water quality and formulation characteristics, consideration of nozzle type determines the sizes of spray droplets and swath patternation. The droplet sizes and flow velocity from air-induction twin-jet nozzles exceed that of single flat fan nozzles, but within similar nozzle type exists no significant differences of spray droplets characteristics upon varying application parameters (Vallet and Tinet, 2013). Furthermore, various sizes of a nozzle type have no significant effect on nominal flow rate (NFR) as compared to different nozzle types with air-tight nozzle adapter, (Vanella et al., 2011). The NFR is a function of ISO nozzle size code (NS), base pressure for nozzle classification $\left(\mathrm{P}_{1}\right)$ and operating pressure $\left(\mathrm{P}_{2}\right)$, with regression coefficient $(\alpha)$ and conversion factor $(\mathrm{GV})$ as constants as in equation 1.

$$
\mathrm{NFR}=\alpha \cdot \mathrm{NS} \cdot \mathrm{GV}\left(\sqrt{\mathrm{P}_{2}} / \sqrt{\mathrm{P}_{1}}\right)
$$

Additionally, a nozzle type determines the degree of drift reduction, drift potential, droplet sizes and ground coverage (Figure 2).

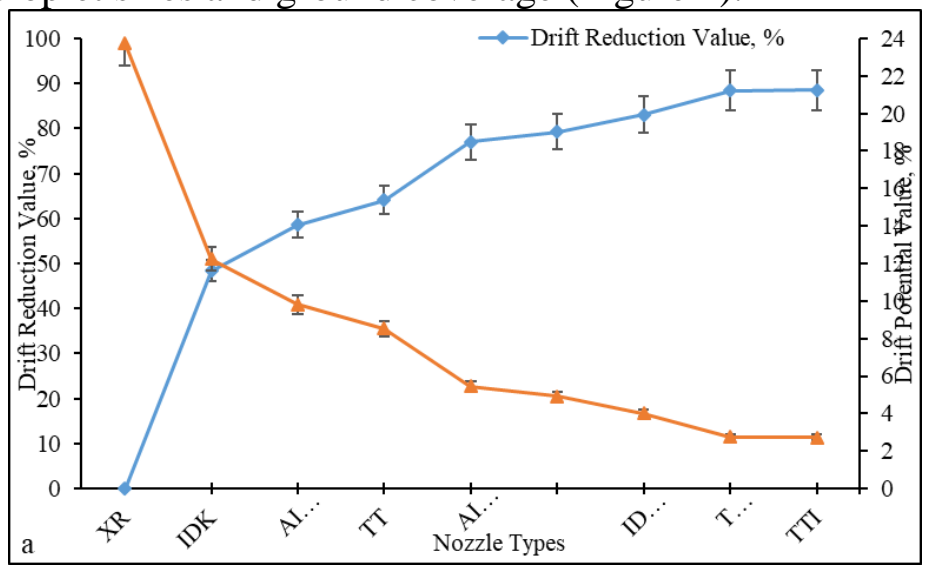




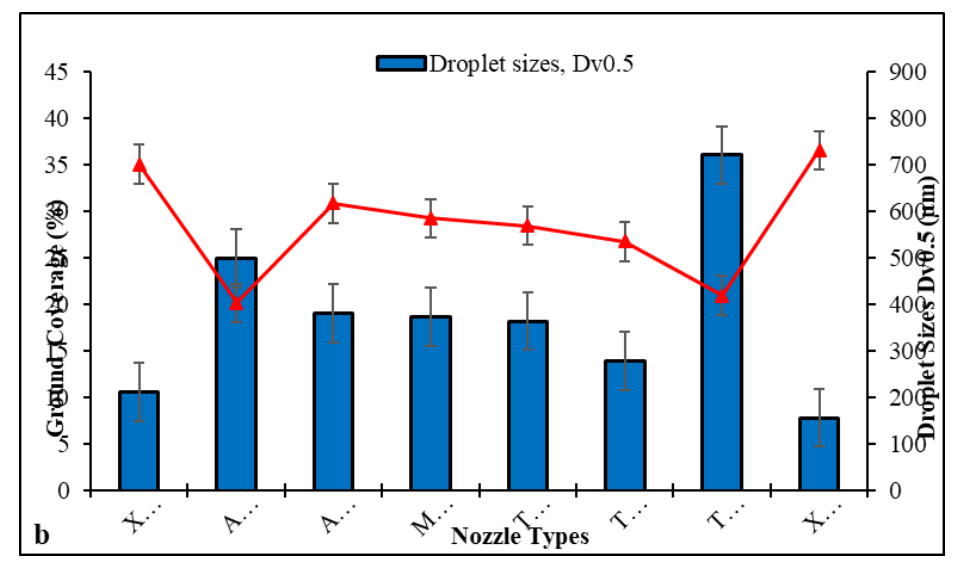

Figure 2: Effect of nozzle types on (a) Drift Potential Value and Drift Reduction Value. Decreasing drift potential value increases drift reduction values (Gil et al., 2014) and (b) Droplet sizes and Ground Coverage. The larger the droplet sizes, the smaller the ground coverage and vice versa (Ferguson et al., 2016).

In evaluating different nozzle types at correct formulation and pressure during spraying, nozzles that produce larger droplets also reduce drift and give maximum surface coverage (Holterman et al., 1997; Ferguson et al., 2015; Ferguson et al., 2016a). In other words, for a particular nozzle type, the larger the size the lesser the drift potential value produced (Gil et al., 2014). In an operation, spray coverage and droplets drift are determined by droplet sizes and velocity (Taylor et al., 2004) as opposed by environmental conditions (Gil et al., 2015), nozzle size and pressure (Sun et al., 2015). In a comparative study, the rate of droplets flow and drifts from different flat fan nozzles varied (Zhao et al., 2014) and the potential drift value was minute when ambient wind velocity was less than $1 \mathrm{~m} . \mathrm{s}^{-1}$ (Gil et al., 2015). Therefore, choosing correct nozzle type for application is necessary to produce ideal spray droplets characteristics.

For farmers to enhance effective pesticide spray at a reduced drift, airinduction flat fan nozzles have proven to be better than conventional hollow cone nozzles. This is because air-induction flat fan nozzles produce coarser droplets at reduced drift to enhance biological efficacy than hollow cone nozzle which produced very fine spray droplets (Doruchowski et al., 2017). There is a strong significant relationship between nozzle type, pressure and ground coverage, with a convincing data of $414 \mathrm{kPa}$ pressure producing higher droplet number density and quality coarser nozzles improving ground coverage (Ferguson et al., 2016a; Ferguson et al., 2016b). Though nozzle type determines volume of application, its surface coverage does not change (Legleiter and Johnson, 2016). In Garcerá et al., (2017), venturi nozzle type was recommended as compared to standard cone for pesticide spraying in citrus protection, however no significant difference $(\mathrm{p}<0.05)$ was recorded in 
using both nozzles. In contrast, hollow cone produced finest droplets of pesticides to extensively control disease in waterhemp than nozzles with larger droplets (Doll et al., 2005). In a research to measure droplet sizes from different nozzles, Sun et al., (2017) reported that, effective penetration of droplets through canopies is best achieved by using nozzles that produce smaller spray droplet sizes. Irrespective of droplets spectrum, volume median diameter of Dv0.1, Dv0.5 and Dv0.9 are affected by nozzle type to yield an approximate relative span of 1 (Creech et al., 2015). Hence, the better the spray relative span (RS), the atomiser and uniformity of droplets from nozzles (Wolf et al., 2009). RS is a measure of variability of spray droplets in the spray plume as in equation 2.

$$
\mathrm{RS}=\left[\mathrm{D}_{\mathrm{V} 0.9}-\mathrm{D}_{\mathrm{V} 0.1}\right] / \mathrm{D}_{\mathrm{V} 0.5}
$$

Where; $\mathrm{D}_{\mathrm{v} 0.9} \cong$ Particle size, below which $90 \%$ of the volume of droplets exist, $\mathrm{D}_{\mathrm{v} 0.5} \cong$ Particle size, below which $50 \%$ of the volume of droplets exist and Dv0.1 $\cong$ Particle size, below which $10 \%$ of the volume of droplets exist (Matthews, 2000). Though nozzle type determines ground spray coverage, it is largely marked by application rate such that reducing the rate enhanced homogeneity of spray distribution but reduced ground spray deposition (Musiu et al., 2019).

\section{Effect of Nozzle Spacing on Pesticide Spray Swath and Coverage}

Nozzle spacing measures the gap between two nozzles on a boom. The horizontal positioning of nozzles for effective application ranges from 25 to $100 \mathrm{~cm}$ which is confirmed to be about $57 \mathrm{~cm}$, (Khurana et al., 2007). Wolf, (2002) indicated that flat fan nozzles produce excellent surface coverage when spaced between $50-75 \mathrm{~cm}$ on a boom and at $50 \mathrm{~cm}$ spraying height. Ferguson et al. (2016b) noted that nozzles spacing on the boom has significant effect on ground spray coverage and proposed for alternating nozzles on the boom. Such arrangement would prevent spray pockets during pesticide application. Likewise, Pascuzzi and Cerruto, (2015) commented on the mean folia deposition as a responsibility of nozzle orientation. For a uniform spray coverage on closed-canopies, nozzles should be relatively mounted closer to one another but that could increase application density as well (Foque et al., 2012a). The ideal nozzle spacing on the boom depends on the nozzle type and angle but the wider the angle, the farther and higher the nozzles are positioned (Malik et al., 2012). In a study to determine nozzle spacing effect on drift, Murphy et al. (2000) maintained that irrespective of the spray formulation, droplets are exposed to the highest airborne drift when nozzles are positioned at $50 \mathrm{~cm}$ apart on the boom. Nozzles are also capable of discharging the right spray volume when arranged on vertical boom (Foque et al., 2012b). Therefore, depending on spray patternation required, the spray swath (W) of each nozzle must be taken into consideration (Figure 3) (Ye et al., 2003). 


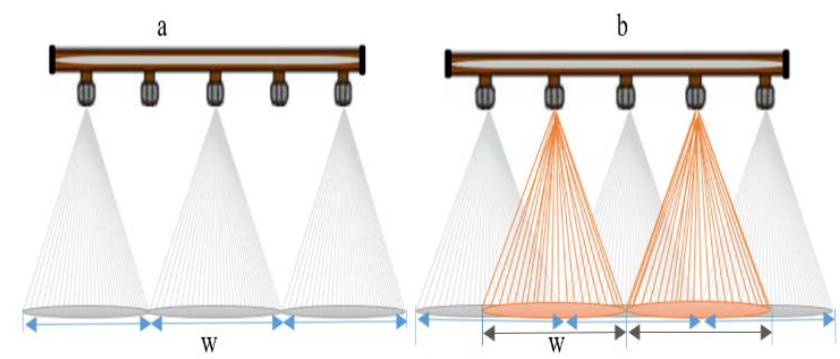

Figure 3. Boom spray swath patternation, (a) Non-Overlap spray swath and (b) an Overlapped spray swath.

Swath $(\mathrm{W})=[\mathrm{GPM} \times 5940] /[\mathrm{S} \times \mathrm{GPA}]$

Where; $\mathrm{W}=$ width spray by each nozzle (inches), GPM = nozzle flow rate (gallons per minute); GPA = sprayer application rate (gallons per acre); $\mathrm{S}=$ speed (miles per hour),

$5,940=$ a constant for conversion of unit.

\section{Effect of Spraying Height on Spray Droplets Distribution \\ 5.1. Ground sprayers}

The height regimes at which nozzles are positioned are significant for drift predicting and spray distribution, therefore variations in boom heights could influence the spray outcome. Though the importance of boom height is not of much concern in nozzle selection, it determines spray patternation and direction (Al Heidary et al., 2014). Al-Gaadi, (2010) field experiment on ground sprayers indicated that varying spraying heights is proportional to application rate error and uniformity of distribution, but decreases application density and spread. With droplets, increasing nozzle height produces smaller volume median diameter (Tuck et al., 1997), whiles decreasing spraying height reduces drift accordingly (Nuyttens et al., 2007b). By raising boom height to maximise spray droplets distribution, drift ensues (Smith et al., 2000), making it difficult to determine optimum height regime for pesticide spraying (Ling, 2011). Investigation for optimum spraying height for pesticide application above all crop canopies is paramount in plant protection. In similar study where upward adjustment of nozzle height maximized drift, Miller et al. (2011) and Zhao et al. (2014) observed that such an adjustment further induced air-borne spray drift. Therefore, working with optimum spraying height is the sole objective for pesticide application. In a test bench (Balsari et al., 2007), at $100 \mathrm{~cm}$ spraying height, potential drift value was high but reduced along decreasing spraying height regimes. Ye et al. (2003) pointed out that nozzle height, spacing and droplet patterns are the principal cause of spray overlap which affected uniformity and chemical efficiency. In support, Al-Gaadi, (2010) reported that spray distribution from flat fan nozzles is better than hollow cone nozzles for all height regimes. The band and width spraying of 
herbicide requires correct upward positioning of the nozzle on the boom, because raising the nozzles to a suitable height regime determines the spray width (Jensen et al., 2013) (Figure 4). Such nozzle spacing and spraying height should not unnecessarily create spray pockets as that decreases efficiency of pesticide spraying.
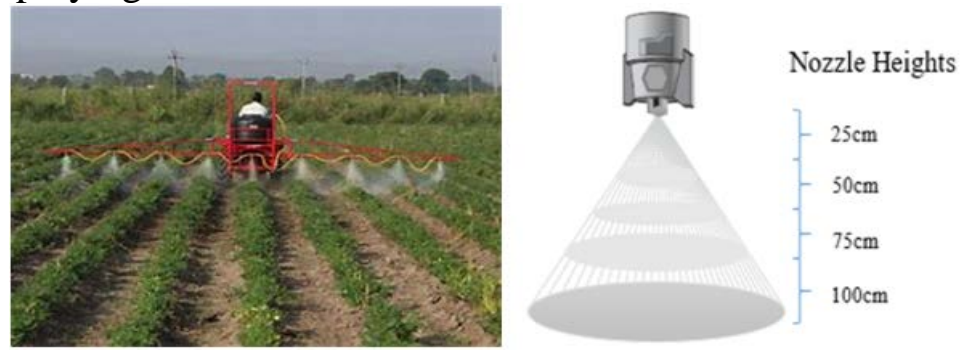

Figure 4. Nozzle Height Regimes and Spray Swath.

For a suitable ground spray cover, nozzle spacing and height regimes should be adjusted concurrently (Miller and Butler Ellis, 2000), since spray drift is aided by physical variables, droplet size and velocity (Taylor et al., 2004). In modelling spray drift, Holterman et al. (1997) summarized that boom height, prevailing wind speed and nozzle size greatly affect potential spray drift. The wider the nozzle angle and spacing, the higher the position of the boom and vice versa. Nozzles having $120^{\circ}$ angle are spaced at 50, 75 or $100 \mathrm{~cm}$ apart and 60, 75 and $100 \mathrm{~cm}$ boom height respectively due to wider spray span, while $110^{\circ}$ nozzle tip angles are spaced at $50 \mathrm{~cm}$ and $75 \mathrm{~cm}$ at corresponding $50 \mathrm{~cm}$ and $75 \mathrm{~cm}$ heights. For $80^{\circ}$ nozzle types, a spacing of 50 $\mathrm{cm}$ is required on the boom at a height of $75 \mathrm{~cm}$, but reducing the height from $50 \mathrm{~cm}$ greatly minimized droplet drift among ground sprayers (Nuyttens et al., 2007b; User's Guide, 2013; Patel et al., 2017). Also, increasing spraying heights from $0.35 \mathrm{~m}$ to $0.95 \mathrm{~m}$ accordingly increased spray swath patternation from $0.31 \mathrm{~m}$ to $0.53 \mathrm{~m}$ across a uniform surface (Maski and Durairaj, 2010). This shows that increasing spraying height rather increases ground coverage, however, there is the need to consider optimum height regimes that effectively increase deposition at reduced spray drift. In using pneumatic ground sprayer at vineyard application, a maximum of $0.5 \mathrm{~m}$ above crop canopies produced suitable spray deposition and ground coverage (Pascuzzi and Cerruto, 2015). This height regime produced ideal spray overlap from nozzles and uniformity of spread but lowering the height resulted in low droplet penetration into the crop canopy architecture.

\subsection{Aerial sprayers}

Both manned aerial aircrafts and unmanned aerial vehicles (UAV) such as drones are used in modern pesticide application and their spraying heights influence ground coverage and driftability (Giles and Billing, 2014; Yamane 
and Miyazaki, 2017; Sheu et al., 2919). The UAV technology aims at overcoming health implications associated with manual pesticide applications (Mogili1 and Deepak, 2018). This is because the application process is purely remote control. According to Zhang et al. (2017), spraying at $50 \mathrm{~cm}$ height improves deposition on crop canopies at reduced spray drift from UAV. Also, application of glyphosate pesticide over crop canopies was appropriated by using man aerial vehicle (airplane) at different spraying height regimes of 3.7, 4.9, and $6.1 \mathrm{~m}$ (Huang et al., 2017). These heights enhanced spray deposition and efficacy at different levels of crop injury detection. The spraying height regimes of UAV and airplane are shown in Figure 5. There is much precision of deposition at reduced spray drift on the case of drones (Figure 5a) as compared to aircraft pesticide spraying where spray drift occurred as a result of wind interference (Figure 5b). In view of that, there is the need to operate at optimum spraying height to enhance uniformity of droplets distribution on plant surfaces without drift to non-target sites.

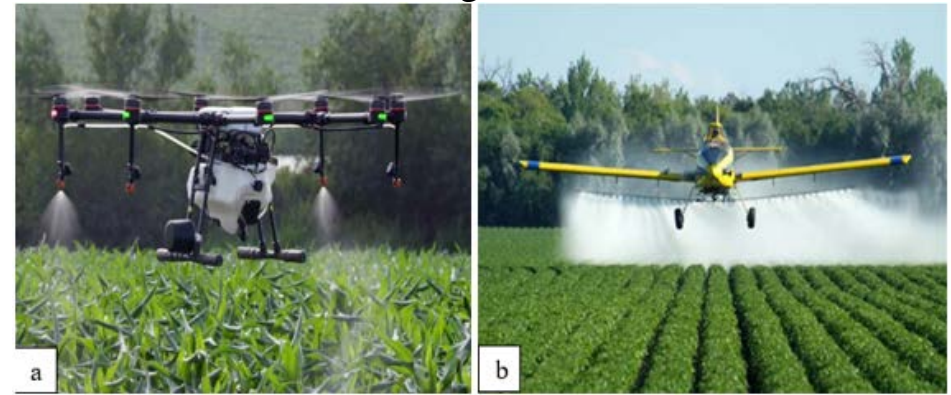

Figure 5. Aerial pesticide spraying with (a) unmanned aerial vehicle (UAV) and (b) manned aerial vehicle.

\section{Conclusion}

Mechanical deposition of pesticides on crops in crop protection is achieved through nozzles. The nozzles are moulded from stainless steel, ceramic, plastic and brass materials. Air induction flat fan and hollow cone nozzle types are often used to enhance spray droplets uniformity and surface coverage at a reduced drift. Nozzle tip colour, ISO number and angle size are used in nozzles selection for application. The larger the ISO value, the bigger the droplet sizes while the wider the nozzle angle, the farther the swath. The review evolved that, on a boom, nozzles are spaced for overlap and nonoverlap sprays and lifted high enough to give correct surface coverage. Different spacing and spraying height regimes are adopted depending on plant canopy and the purpose of spraying. Horizontal spacing between 50 and 100 $\mathrm{cm}$ and vertical boom height of 50 to $100 \mathrm{~cm}$ for nozzle angles of $80^{\circ}, 110^{\circ}$ and $120^{\circ}$ are often adopted for both ground and aerial pesticide application.

Nozzles having larger tip angles are spaced farther apart and at higher height regime to produce the needed ground coverage. There were variable nozzle spacing and spraying height regimes for all nozzle configurations in 
crop protection. Because of that, the review suggests the following recommendations for pesticide spraying;

1. Investigation for an optimum nozzle spacing and spraying height orientation for pesticide spraying over crop canopies;

2. Assessing efficiency of spraying from either overlap and non-overlap nozzle spacing at specific height regime; and

3. Determination of spray droplets penetration depth through plant canopies from variable nozzle types at different spraying height regimes and flow pressures. These would give an informed decision on criteria for nozzle selection for pesticide spraying in crop protection.

\section{Acknowledgement}

The authors wish to acknowledge the research funding agencies for the preparation of this article; the National Natural Science Foundation of China (grant number 31601676), the National Key R\&D Program of China (grant number 2017YFD0200900), and the Advanced Talent Research Funding of Jiangsu University (grant number 5501200004).

\section{References:}

1. Adenawoola A.R., Aladesanwa R.D. \& Adenowuro T.D. (2005). Effects of frequency of weeding on the growth and yield of longfruited jute (Corchorus olitorius) in a rainforest area of southwestern Nigeria. Crop Protection 24: 407-411.

2. Aktar M.W., Sengupta D. \& Chowdhury A. (2009). Impact of pesticides use in agriculture: their benefits and hazards. Interdisciplinary Toxicology 2(1): 1-12.

3. Al Heidary M., Douzals J.P., Sinfort C. \& Vallet A. (2014). Influence of spray characteristics on potential spray drift of field crop sprayers: Literature Review. Crop Protection 63: 120-130.

4. Al-Gaadi K.A. (2010). Effect of Nozzle Height and Type on Spray Density and Distribution for a Ground Field Sprayer. J. Saudi Soc. for Agric. Sci. 9(1): 1-22.

5. Armstrong-Cho C., Chongo G., Wolf T., Hogg T., Johnson E. \& Banniza S. (2008). The effect of spray quality on ascochyta blight control in chickpea, Crop Protection 27: 700-709.

6. ASABE 2009. Spray Nozzle Classification by Droplet Spectra. ANSI/ASAE S572. 1.

7. Balsari P., Marucco P. \& Tamagnone M. (2007). A test bench for the classification of boom sprayers according to drift risk. Plant Protection 26: 1482-1489. 
8. Bueno M.R., da Cunha J.P.A.R. \& de Santana D.G. (2016). Assessment of spray drift from pesticide applications in soybean crops. Biosystems Engineering 154: 1-11.

9. Butler Ellis M.C, Miller P.C.H, Tuck C.R, (1997). The effect of some adjuvants on sprays produced by agricultural flat fan nozzles. Crop Protection 16 (1), 41-50.

10. Butler Ellis M.C. \& Tuck C.R. (1999). How adjuvants influence spray formation with deferent hydraulic nozzles. Crop Protection 18: 101-110.

11. Cho S.I. \& Ki N.H. (1999). Autonomous speed sprayer guidance using machine vision and fuzzy logic. Trans. of the ASAE 42:11371144.

12. Creech C.F., Henry R.S., Fritz B.K. \& Kruger G.R. (2015). Influence of Herbicide Active Ingredient, Nozzle Type, Orifice Size, Spray Pressure, and Carrier Volume Rate on Spray Droplet Size Characteristics. Weed Technology 29(2): 298-310.

13. Coscollà C., López A., Yahyaoui A., Colin P., Robin C., Poinsignon Q. \& Yusà, V. (2017). Human exposure and risk assessment to airborne pesticides in a rural French community. Science of the Total Environment 584-585: 856-868

14. Derksen R.C., Ozkan H.E., Paul P.A. \& Zhu H. (2014). Plant canopy characteristics effect on spray deposition. Asp. Appl. Biol. 122, 227235.

15. Doll D.A., Sojka P.E., \& Hallett S.G. (2005). Effect of Nozzle Type and Pressure on the Efficacy of Spray Applications of the Bioherbicidal Fungus Microsphaeropsis amaranthi. Weed Technology 19(4): 918-923.

16. Doruchowski G., Świechowski W., Masny S., Maciesiak A., Tartanus M. \& Bryk H. (2017). Hołownicki R. Low-drift nozzles vs. standard nozzles for pesticide application in the biological efficacy trials of pesticides in apple pest and disease control. Science of the total Environment 575:1239-1246.

17. Douzals J.P., \& Al Heidary M. (2014). How spray characteristics and orientation may influence spray drift in a wind tunnel. International Advances in Pesticide Application. Oxford, United Kingdom.

18. Duvnjak V., Pliestić S., Filipović D., Banaj D. \& Andrić L. (2009). Effect of Orifice wear of boom sprayer nozzles on spray characteristic. Agronomski Glasnik 4.

19. Ellis M., Miller P., Orson J., Alexander L., Carpenter P., Cooper S., Glass C.R., Gummer A.P., Magri B. \& Robinson T. (2008). 
Minimizing drift while maintaining efficacy-the role of air-induction nozzles. Aspects Appl. Biol. 84: 59-66.

20. Ferguson J.C., Hewitt A.J. \& O’Donnell C.C. (2016b). Pressure, droplet size classification and nozzle arrangement effects on coverage and droplet number density using air-inclusion dual fan nozzles for pesticide application. Plant Protection 62: 231-238.

21. Ferguson J.C., Chechetto R.G., Hewitt A.J., Chauhan B.S., Adkins S.W., Kruger G.R. \& O’Donnell C.C. (2016a). Assessing the deposition and canopy penetration of nozzles with different spray qualities in an oat (Avena sativa L) canopy. Crop Protection 81: 14 -19 .

22. Ferguson J.C., O'Donnell C.C., Chauhan B.S., Adkins S.W., Kruger G.R., Wang R., Ferreira P.H.U. \& Hewitt A.J. (2015). Determining the uniformity and consistency of droplet size across spray drift reducing nozzles in a wind tunnel. Crop Protection 76: 1-6.

23. Foque D., Pieters J.G. \& Nuyttens D. (2012a). Spray deposition and deposition in a bay laurel crop as affected by nozzle type, air assistance and spray direction when using vertical booms. Crop Protection 41: 77-87.

24. Foqué D., Braekman P., Pieters J.G. \& Nuyttens D. (2012b). A vertical spray boom application technique for conical bay laurel (Laurus nobilis) Plants. Crop Protection 41: 113-121.

25. Garcerá C., Román C., Moltó E., Abad R., Insa J.A., Torrent X., Planas S. \& Chueca P. (2017). Comparison between standard and drift reducing nozzles for pesticide application in citrus: Part II. Effects on canopy spray distribution, control efficacy of Aonidiella aurantii (Maskell), beneficial parasitoids and pesticide residues on fruit. Crop Protection 94: 83-91.

26. Gaytan I., Nicolas B., Gouriou F., Leru J.P. \& Mallarach J. (2018). Effect of working pressure, fluid temperature, nozzle type and nozzle orifice size, on spray characteristics using viscous feed additive DL-2-hydroxy-4-(methylthio)-butanoic-acid. Powder Technology 336: 383-392.

27. Gil E., Balsari P., Gallart M., Lloren J., Marucco P., Andersen P.G., Fabregas X. \& Llop J. (2014). Determination of drift potential of different flat fan nozzle on a boom sprayer using a test bench. Crop Protection 56: 58-68.

28. Gil E., Gallart M., Balsari P., Marucco P., Almajano A.P. \& Llop J. (2015). Influence of wind velocity and wind direction on measurements of spray drift potential of boom sprayers using drift test bench. Agricultural and forest meteorology 202: 94-101. 
29. Giles D.K. \& Billing R. (2014). Unmanned Aerial Platforms for Spraying: Deployment and Performance. Aspects of Applied Biology 122: 63-69.

30. Guler H., Zhu H., Ozkan H.E. \& Ling P. (2012). Characterization of hydraulic nozzles for droplet size and spray coverage. Atomization Sprays 22: 627-645.

31. Hanks J.E., Jones E.J., Wills G.H. \& Mack R.E. (2002). Effects of nozzle types and glyphosate formulations on spray droplet size and patterns. Proceedings of Southern Weed Science Society 55: 190.

32. Hanna H.M., Robertson A.E., Carlton W.M., Wolf R.E. (2009). Nozzle and carrier application effects on control of soybean leaf spot diseases. Appl. Eng. Agric. 25: 5-13.

33. Hassen N.S., Sidik N.A.C., Sheriff J.M. (2013). Effect of nozzle type, angle and pressure on spray volumetric distribution of broadcasting and banding application. Journal of Mechanical Engineering Research 5(4): 76-81.

34. Hewitt A.J. \& Hermansky C.G. (1997). The effects of liquid properties on spray formation, Proceedings of the Chemical Show, New York, NY.

35. Hofman V. \& Solseng E. (2004). Spray Equipment and Calibration, Agricultural and Biosystems Engineering, Fargo, North Dakota.

36. Holterman H.J., van de Zande J.C., Porskamp H.A.J. \& Huijsmans J.F.M. (1997). Modelling spray drift from boom sprayers. Computers and Electronics in Agriculture 19(1): 1-22.

37. Huang Y.B., Ouellet-Plamondon C.M., Thomson S.J. \& Reddy K.N. (2017). Characterizing downwind drift deposition of aerially applied glyphosate using RbCl as tracer. Int J Agric \& Biol Eng. 10(3): 3136.

38. Jamar L., Mostade O., Huyghebaert B., Pigeon O. \& Lateur M. (2010). Comparative performance of recycling tunnel and conventional sprayers using standard an drift-mitigating nozzles in dwarf apple orchards. Crop Protection 29: 561-566.

39. Jensen P.K., Lund I. \& Nuyttens D. (2013). Spray liquid distribution and biological efficacy of commercially available nozzles used for precision weed control. Biosystems Engineering 16(4): 316-325.

40. Jia WD., Li Ch., Mao HP. (2010). CFD Simulation of Three MultiFoil Shields: The 21st International Symposium on Transport Phenomena, Kaohsiung City, Taiwan.

41. Khurana R., Singh S.K. \& Dixit A. (2007). Nozzle Spacing on Sprayer Boom. Journal of Agricultural Engineering 44(3): 87-91. 
42. Klein R., Golus J. \& Nelms K. (2009). The Effect of Adjuvants, Pesticide Formulation, and Spray Nozzle Tips on Spray Droplet Size. JAI 6(6).

43. Legleiter T.R. \& Johnson W.G. (2016). Herbicide coverage in narrow row soybean as influenced by spray nozzle design and carrier volume. Crop Protection 83: 1-8.

44. Ling S., Xia Z. \& Hongsheng W. (2011). Experimental research on spray distribution uniformity of fan nozzle (Abhilash and Singh). Journal of Yunnan Agricultural University 26(3): 389- 394

45. Lipp \& Charles W. (2012). Practical Spray Technology: Fundamentals and Practice, ISBN 978-0-578-10090-6.

46. Malik R.K., Pundir A., Dar S.R., Singh S.K., Gopal R., Shankar P.R., Singh N., Jat M.L. (2012). Sprayers and Spraying Techniques - A manual, CSISA, IRRI and CIMMYT, 20 pp.

47. Maski D. \& Durairaj D. (2010). Effects of charging voltage, application speed, target height, and orientation upon charged spray deposition on leaf abaxial and adaxial surfaces. Crop Protection 29(2): 134-141.

48. Matthews G.A. (1999). Application of Pesticides to Crops. Imperial College Press, London.

49. Matthews G.A. (2000). Pesticide Application Methods. 3rd ed. Oxford, UK: Blackwell Science.

50. Miller P.C.E. \& Butler Ellis M.C. (2000). Effects of formulation on spray nozzle performance for applications from ground-based boom sprayers. Crop Protection 19: 609-615.

51. Miller P.C.H., Ellis M.C.B., Lane A.G. \& Tuck C.R. (2011). Methods for minimising drift and off-target exposure from boom sprayer applications. Asp. Appl. Biol. 106, 281-288.

52. Mogili1 U.M.R. \& Deepak B.B.V.L. (2018). Review on Application of Drone Systems in Precision Agriculture. Procedia Computer Science 133: 502-509.

53. Musiu E.M., Qi L. \& Wu Y. (2019). "Spray deposition and distribution on the targets and losses to the ground as affected by application volume rate, airflow rate and target position." Crop Protection 116: 170-180.

54. Mueller T.C. \& Womak A.R. (1997). Effect of formulation and nozzle type with isopropylamine and trimesium salts of glyphosate. Weed Technology 11: 639-643.

55. Murphy S.D., Miller P.C.H. \& Parkin C.S. (2000). The Effect of Boom Section and Nozzle Configuration on the Risk of Spray Drift. J. agric. Engng Res. 75: 127-137. 
56. Nasr G.G., Yule A.J. \& Bendig L. (2002). Introduction to Industrial Sprays. In Industrial Sprays and Atomization (pp. 1-6). Springer, London.

57. Nuyttens D., Baetens K., De Schampheleire M. \& Sonck B. (2007a). Effect of nozzle type, size and pressure on spray droplet characteristics. Biosystems Engineering 97 (3): 333-345.

58. Nuyttens D., De Schampheleire M., Baetens K. \& Sonck B. (2007b): The influence of operator-controlled variables on spray drift from field crop sprayers. Transactions of the ASABE 50(4):1129-1140.

59. Nuyttens D., De Schampheleire M., Verboven P. \& Sonck B. (2010). Comparison between indirect and direct spray drift assessment methods. Biosystems Eng. 105(1): 2-12.

60. Nuyttens D., Taylor W.A., De Schampheleire M., Verboven P. \& Dekeyser D. (2009). Influence of nozzle type and size on drift potential by means of different wind tunnel evaluation methods. Biosystems Engineering 103: 271-280.

61. Pascuzzi S. \& Cerruto E., (2015). Spray deposition in tendone vineyards when using a pneumatic electrostatic sprayer. Crop Protection 68: 10-11.

62. Parafiniuk S., Milanowski M. \& Subr A.K. (2015). The influence of the water quality on the droplet spectrum produced by agricultural nozzles. Agriculture and Agricultural Science Procedia 7: 203-208.

63. Patel M.K., Praveen B., Sahoo H.K., Patel B., Kumar A., Singh M., Nayak M.K. \& Rajan P. (2017). An advance air-induced air-assisted electrostatic nozzle with enhanced performance. Computers and Electronics in Agriculture 135: 280-288. http://dx.doi.org/10.1016/j.compag.2017.02.010

64. Reus J., Leendertse P., Bockstaller C., Fomsgaard I., Gutsche V., Lewis K., Nilsson C., Pussemier L., Trevisan M. \& Van Der Werf H. (2002). Comparison and evaluation of eight pesticide environmental risk indicators developed in Europe and recommendations for future use. Agriculture, Ecosystems and Environment 90: 177-187.

65. Robert E.W. (2002). Nozzle Types Available for boom Sprayer Applications of Crop Protection Products, Kansas State University.

66. Sanderson A.J., Hewitt A.J., Huddleston E.W. \& Ross J.B. (1997). Relative drift potential and droplet size spectra of aerially applied Propanil formulations. Crop Prot. 16: 717-721.

67. Sheu B-H., Chiu C-C., Lu W-T., Lien C-C., Liu T-K. \& Chen W-P. (2019). "Dual-axis rotary platform with UAV image recognition and tracking." Microelectronics Reliability 95, 8-17. 
68. Smith D.B., Bode L.E. \& Gerard P.D. (2000). Predicting ground boom spray drift. Transactions of ASAE 43(3): 547-553.

69. Sukumaran S., Manes G.S., Singh S.K., Singh A. \& Dixit A. (2013). Effect of spraying pressure and usage on discharge rate and wear of hollow cone nozzle having different nozzle tip material. Journal of Agricultural Engineering 50(1).

70. Sun C., Ding W., Zhou L., Qiu W. \& Gu J. (2017). Design and application of a system for droplet-size measurement in the field based on micro-distance imaging technology. Crop Protection 96, 228-236.

71. Sun W., Qichao L. \& Yongcun F. (2015). Preparation Analysis on Effect Factors of Spraying Quality for Boom Sprayer. Advanced Science and Technology Letters 111.

72. Taylor W.A., Womac A.R., Miller P.C.H. \& Taylor B.P. (2004). An attempt to relate drop size to drift risk. Proceedings of the International Conference on Pesticide Application for Drift Management, 210-223.

73. Tuck C.R., Butler Ellis M.C. \& Miller P.C.H. (1997). Techniques for measurement of droplet size and velocity distributions in agricultural sprays. Crop Protection 16(7): 619-628.

74. User's Guide (2013). User's Guide to Spray Nozzles - TeeJet. http://teejet.it/media/40076/user's\%20guide\%20to\%20spray\%20no zzles_2013_lo-res-sequential.pdf

75. Vallet A. \& Tinet C. (2013). Characteristics of droplets from single and twin jet air induction nozzles: A preliminary investigation. Crop Protection 48: 63-68.

76. Vanella G., Salyani M. \& Balsari P. (2011). Effect of the nozzle adaptor of sprayer calibrator on flow rate measurements. Crop Protection 30: 1043-1047.

77. Wolf R.E. (2002). Nozzle Types Available for Boom Sprayer Applications of Crop Protection Products, Kansas State University.

78. Wolf R.E. (2004). Ground field sprayers for drift management. Kansas State University, KS 66506 USA, Invited Presentation Articles 107: In: http://pep.wsu.edu/drift04/pdf/proceedings/pg107108_Wolf.pdf.

79. Yamane S. \& Miyazaki M. (2017). Study on Electrostatic Pesticide Spraying System for Low-Concentration, High-Volume Applications. Japan Agricultural Research Quarterly: JARQ, 51(1): 11-16. https://doi.org/10.6090/jarq.51.11

80. Yarpuz-Bozdogan N., Atakan E., Bozdogan A.M., Yilmaz H., Daglioglu N., Erdem T. \& Kafkas E. (2011). Effect of different 
pesticide application methods on spray deposits, residues and biological efficacy on strawberries. Afr. J. Agric Res. 6: 660-670.

81. Ye Y., Zhibiao W. \& Shengming H. (2003). Problems and Prospect of Developing Pesticides. Journal of South China University of Tropical Agriculture 9(2): 26-31.

82. Zhao H., Xie C., Liu F., He X., Zhang J. \& Song J, 2014. Effect of sprayers and nozzles on spray drift and terminal residues of imidacloprid on wheat. Crop protection 60:78-82.

83. Zhang Y.L., Lian Q. \& Zhang W. (2017). Design and test of a sixrotor unmanned aerial vehicle (UAV) electrostatic spraying system for crop protection. Int J Agric \& Biol Eng. 10(6): 68-76. 